\title{
Depoimentos e Vivências de Mulheres nos Cursos de Computação da Universidade Tecnológica Federal do Paraná
}

\section{Testimonials and Experiences of Women in the Computing Courses at the Technological Federal University of Paraná}

\author{
FABIANE ALVES DE LIMA \\ Universidade Tecnológica Federal do Paraná
}

\begin{abstract}
Resumo: Este artigo apresenta um estudo de caso sobre mulheres na computação, no contexto específico da Universidade Tecnológica Federal do Paraná. De modo a delimitar o tema e construir a argumentação, fundamenta-se na história da tecnociencia, da computação, nos estudos em Ciência, Tecnologia e Sociedade, e nos estudos feministas. Com base na literatura, assume-se que a computação vem sendo historicamente construída no intuito de manter as barreiras que dificultam a participação plena de mulheres e de outras minorias. A metodologia utilizada é a pesquisa qualitativa. Os dados foram coletados através de entrevistas, onde algumas mulheres puderam externar suas vivencias, façanhas e percalços nestes cursos. Suas falam corroboraram o estudo teórico realizado previamente e confirmaram que um dos fatores que mais prejudicam o acesso das mulheres nas Ciências Exatas é a ideia equivocada que a sociedade construiu a respeito das mulheres, atribuindo-Ihe falsas limitações por causa de seu sexo.
\end{abstract}

Palavras-chave: Computação. Tecnociência. Feminismo. Mulheres.

\begin{abstract}
This paper presents a case study on women in Computer Science, framed within the specific context of the Technological Federal University of Paraná. In order to better define its subject and develop its argument, it grounds itself on the History of Technoscience, of Computer Science, on the studies in Science, Technology and Society, and Feminist Studies. Based on the aforementioned literature, it is presumed that Computer Science has been historically constructed with an intent on preserving the barriers for women's full participation, as well as for other social minorities. The methodology employed was qualitative research. Data was collected through interviews, in which some women reported their experiences, their feats and their issues throughout these courses. These findings corroborate previous theoretical studies and confirm that one of the factors that hinder women's access to Exact Sciences are the erroneous socially constructed notions that attribute false limitations on women based on their sex.
\end{abstract}

Keywords: Computing. Technoscience. Feminism. Women 


\section{Introdução}

Como ser social, o ser humano não pode ser compreendido fora do meio que habita, nem suas ações. E é no seio da sociedade que as finalidades e as prioridades da pesquisa e da tecnologia são determinadas, e por essa mesma sociedade elas são levadas a cabo e concretizadas (VIEIRA PINTO, 1979). Nas sociedades ocidentais um valor bastante presente é a ideia de que o progresso tecnológico se dá de forma linear, constante, inevitável, apontando para um futuro próspero; segundo estas ideias, as ferramentas tecnocientíficas não passariam de ferramentas neutras atuando no auxílio do alcance deste progresso. Assim, dá-se maior prioridade aos conjuntos de conhecimentos que possuam grande aplicação prática ou levem a transformações julgadas positivas pela parcela da população em condições de levar tais ações adiante - pesquisadores, governos e instituições -, de modo que alguns conhecimentos acabam por ganhar maior importância que outros, e consequentemente, maiores investimentos. Essa mentalidade ingênua pode ser denominada determinismo tecnológico, pois vê a tecnologia e a ciência como soluções para os males do mundo, e não vê, ou ignora, os valores sociais embutidos nos artefatos pelos seus projetistas (BIJKER; PINCH, 1987; WINNER, 1986).

Entretanto, alguns campos de investigação - como os estudos em Ciência, Tecnologia e Sociedade - têm questionado a ideia de neutralidade da tecnociência, e que seu desenvolvimento sempre conduz ao progresso. "Tendo como objeto de estudo os aspectos sociais da tecnociência, os estudos em CTS visam investigar os usos, consequências e significados da tecnociência. Devido aos diferentes enfoques que dá ao assunto por diferentes profissionais e estudiosos, trata-se de um campo interdisciplinar" (CARVALHO; CASCAES; SPANGER. In: CARVALHO, et al., 2009. p. 133-134). Esses questionamentos abrem caminho para uma forma alternativa de pensar a produção tecnocientífica, seus usos e aplicações, além de instigar a busca por transformações sociais verdadeiras e inclusivas de grupos historicamente excluídos desse processo - como é o caso das mulheres, que tiveram importância crucial no desenvolvimento das tecnologias da Computação mas tiveram sua participação invisibilizada, e suas capacidades intelectuais desacreditadas, assunto de que este estudo vai tratar -, de modo a empoderar e dar visibilidade a tais grupos, reconhecendo-os como agentes atuantes na pesquisa e no desenvolvimento tecnológico e, consequentemente, como atores que contribuem para a construção da sociedade em todos os seus aspectos.

Dado seu apagamento, invisibilidade, não reconhecimento, e exclusão na participação e no registro da história da técnica e dos empreendimentos intelectuais humanos, mostra-se urgente que mais mulheres se conscientizem de seus papéis como atrizes e agentes dentro da tecnologia e da ciência - e de sua própria história. Esta pesquisa buscou ouvir mulheres estudando e trabalhando na Computação para compreender como se dá essa sua atuação e as eventuais dificuldades que elas encontram. 


\section{Objetivos}

Espera-se que esta pesquisa contribua para uma maior e melhor compreensão dos conceitos aqui apresentados, e almeja-se também que possa auxiliar o desenvolvimento de pesquisas futuras, seja no que diz respeito ao aporte teórico utilizado ou no incremento de dados que possam corroborar esta e outras investigações futuras.

A tecnociencia como um todo e a Computação em particular carecem de exemplos que estejam distantes do popularmente conhecido estereótipo do homem branco heterossexual. A falta de modelos em que se espelhar é um problema bastante discutido na bibliografia que trata da exclusão histórica das mulheres. Carecem, além disso, da desmistificação das práticas da tecnociência.

A presente pesquisa parte do pressuposto de que as mulheres têm consciencia da discriminação histórica que sofrem na tecnociencia e, especificamente, na Computação, e seu objetivo geral pode ser descrito como uma busca pela percepção que as mulheres estudantes e profissionais em Computação têm das colegas, de si mesmas, do cenário em que vivem, e também das eventuais dificuldades por que passam na academia e na profissão.

Em relação aos objetivos espećíficos desta pesquisa, dentro do escopo atingível pela metodologia proposta de estudo de caso, estiveram:

- A coleta, entre as componentes da amostra, de informaç̃ões a respeito delas e da situação que estão e estiveram vivendo, suas expectativas, características, problemas, convergencias e divergencias;

- O diálogo entre pesquisadora e sujeitas de pesquisa, visando a concretização de conhecimentos teóricos e a consequente comparação entre estes saberes;

- O aprimoramento da experiencia e dos saberes das participantes e da pesquisadora.

\section{Metodologia}

O estudo de uma comunidade espećífica e pouco numerosa como a das mulheres atuantes em computação carece de um modo de investigação que deixe evidentes sua autonomia e voz sem preocupar-se muito com generalizações de natureza estatistica dos dados coletados, ao mesmo tempo em que não ignore sua participação e ajude a encontrar soluções para suas eventuais dificuldades. Por este motivo, optou-se utilizar como metodologia de trabalho o estudo de caso. Tal abordagem "tem como principal finalidade desenvolver, esclarecer e modificar conceitos e idéias com vistas à formulação de problemas mais precisos ou hipóteses pesquisáveis para estudos posteriores" (CALEFFE; MOREIRA, 2008. p. 70) e "surge do desejo de entender os fenomenos sociais complexos" (YIN, 2010. p. 24).

Conforme Norbert Elias:

Estudar os aspectos de uma figuração universal no âmbito de uma pequena comunidade impõe à investigação algumas limitaç̃ões óbvias. Mas também tem suas vantagens. O uso de uma pequena comunidade social como foco da investigacão de problemas igualmente encontráveis numa grande variedade de unidades sociais, maiores e mais diferenciadas, possibilita a exploração desses problemas com uma minúcia considerável - microscopicamente, por assim dizer. Pode-se construir um modelo explicativo, em pequena escala, da 
figuração que se acredita ser universal - um modelo pronto para ser testado, ampliado e, se necessário, revisto através da investigação de figurações correlatas em maior escala. (ELIAS; SCOTSON, 2000. p. 20).

A metodologia de estudo de caso se mostra adequada na presente pesquisa pois sua base empírica visa descobrir em profundidade como e porque uma série de eventos acontece em um dado contexto, quando a pesquisadora ou o pesquisador possui pouco ou nenhum controle sobre os eventos. Uma vez que esse tipo de pesquisa busca coletar informações que de outras formas seriam dificeis, os dados coletados são, naturalmente, de ordem qualitativa. Não se pretende fazer, portanto, generalizações estatísticas, mas entender a partir dos dados coletados uma situação-problema específica; as generalizaç̃ões feitas neste tipo de estudo são de ordem analítica, e não aplicáveis a populações ou universos (YIN, 2010).

A amostra escolhida para a coleta dos dados foi restrita geograficamente, uma vez que a pesquisa se limita a mulheres vinculadas à UTFPR (Universidade Tecnológica Federal do Paraná), câ̂mpus de Curitiba, e é do tipo intencional homogênea. Diferente da amostra probabilística, a amostra intencional visa selecionar casos ricos em informaç̃ões e interessantes para o estudo em questão (CALEFFE; MOREIRA, 2008). A amostra, selecionada por "bola de neve", foi composta por oito mulheres e pode ser dividida em dois grupos com número igual de participantes: discentes e docentes. Entre as discentes estão alunas e ex-alunas dos cursos de Bacharelado em Sistemas de Informação e Engenharia da Computação da referida universidade. Entre as docentes, professoras dos mesmos cursos de computação, vinculadas à instituição. Em ambos os grupos as mulheres que os compõem têm histórias de vida e origens diversas, com idade média de 37 anos no grupo das docentes, e 23 anos no grupo das discentes. O número da amostra foi determinado conforme a quantidade de estudantes e professoras que se dispuseram a serem entrevistadas. Teve-se o cuidado de se manter o mesmo número de entrevistadas em ambos os grupos. Considerou-se também o pouco tempo disponível para a realização da pesquisa e tratamento dos dados como fator crucial para a limitação do tamanho da amostra. As entrevistas foram realizadas no período entre março e julho de 2014 com o uso de filmagens em vídeo, cuja autorização das participantes foi concedida estritamente para os objetivos desta pesquisa. Em seguida, as filmagens foram transcritas e decupadas para posterior análise.

\section{Referencial teórico}

Como parte de uma sociedade que prioriza um tipo específico de indivíduo, a tecnociência têm sido, ao longo da história, essencial na definição das identidades masculinas, porque em geral é por eles definida e levada a cabo. Projetada e produzida em função desses indivíduos, e desconsiderando as necessidades específicas de todas as outras pessoas, essa construção da tecnologia e da ciência como essencialmente masculina é justamente oposta à feminilidade normativa. Austero e transformador do mundo natural é o homem; singela e ligada à natureza e aos seus ciclos, a mulher. Por isso, algumas áreas do conhecimento acabam por concentrar maior número de homens - geralmente aquelas que conquistaram maior prestígio social, melhor remuneração, e melhor posicionamento na hierarquia dos saberes - , enquanto outras 
são consequentemente dominadas pelas mulheres (SCHIEBINGER, 2001). A partir dos anos 1970 , as feministas passaram a questionar as verdades absolutas e estabelecidas da produção tecnocientífica através de um resgate das contribuições das mulheres à ciência e da identificação das barreiras que impedem um acesso mais amplo e irrestrito à elas (WAJCMAN, 2006).

Londa Schiebinger, destacando a mutabilidade desse sistema, afirma que os estereótipos a respeito de homens e mulheres são características que "não são inatas, nem tampouco arbitrárias. Elas são formadas por circunstâncias históricas. Elas também podem mudar com as circunstâncias históricas" (SCHIEBINGER, 2001. p. 145). É possível perceber, então, que essa separação em esferas diferentes e opostas da atuação de homens e mulheres na sociedade, da mesma forma que reforça diferenças, também reflete as estruturas de poder que atuam na busca da permanência dessas diferenças sociais (LUBAR. In: HOROWITZ; MOHUN, 1998).

É importante lembrar também que os estereótipos influem de modo direto no que é percebido como real. Quanto mais em desvantagem está um grupo social, mais suas representações serão distorcidas e reduzidas, enquanto aprisionadas em estereótipos. Essa estratégia é especialmente eficaz porque permite uma rápida associação com estereótipos, onde se destacam as características-chave do outro para defini-lo tão somente a partir e em função delas. Os estereótipos "fixam limites", e excluem tudo o que não se encaixa (HALL, 2003). No caso das mulheres, as marcas dos estereótipos podem se apresentar através do uso de cosméticos e de certos tipos de roupas - como babados, saias, bordados, motivos florais etc - e da manifestação de comportamentos - como o sentar-se de pernas juntas, não manifestar opinião em público, restrição de movimentos físicos, não tomar parte em atividades físicas etc ${ }^{35}$

Como parte de uma complexa trama social que valoriza certos conhecimentos (e produtores de conhecimentos) em detrimento de outros, está o próprio conceito de tecnologia. Buscando uma definição para o conceito, Álvaro Vieira Pinto elencou quatro definições correntes para o termo (VIEIRA PINTO, 2005): a tecnologia como campo de estudo, como manifestação material da técnica, como conjunto de técnicas de que dispõe um povo, e, finalmente, a tecnologia como ideologia, como processo e constructo social, constituída e constituinte da sociedade. Assim, a tecnologia tem sido definidora e vem sendo também definida e produzida em função da masculinidade e, em oposição, também aos ideais da feminilidade normativa. Desse modo, o que é visto como "masculino" sempre teve estreitos laços com o que é "tecnológico" e "científico", e o feminino, com o mundo natural, portanto, anti-tecnológico. A importância atribuída pela sociedade a essas diferentes esferas é separada por desigualdades que negam a grande diversidade existente nos distintos agrupamentos humanos.

Apesar de recente, na história da informática existem grandes dificuldades na incorporação e no creditamento de alguns dos atores que contribuíram para o desenvolvimento da área.

35 Dois livros tratam em profundidade como a indústria dos cosméticos e os padrões de beleza têm contribuído para a manutenção da subordinação das mulheres através dos estereótipos femininos: "O Mito da Beleza", de Naomi Wolf (1992), e "Beauty and Misoginy", de Sheila Jeffreys (2005). 
Enquanto grandes $\mathrm{CEOs}^{36}$, em geral pessoas de gerência e administração, se sobressaem e acabam por serem transformados em um tipo específico de celebridades na mente do público geral, pessoas de fora dessa elite, cujo esforço foi essencial para o campo, acabam por ser invisibilizadas. Conforme Ensmenger (2010), a dificuldade em relatar a história dessas pessoas se dá, principalmente, em função de que suas atividades raramente são registradas, o que acaba por fazer com que os historiadores se foquem em dados facilmente identificáveis. 0 autor também defende que esse mesmo recorte histórico, focado na invenção e no desenvolvimento do objeto, dá a impressão de que a evolução desses artefatos se deu em constante progressão linear, e promove uma visão determinística do desenvolvimento desta área em particular. $\mathrm{O}$ foco da historiografia em personagens específicos, além de conduzir a uma leitura preferencial dos fatos, também faz esquecer que raramente eram os grandes nomes do campo que desenvolviam os produtos através dos quais ficaram famosos. Na maior parte das vezes esses "heróis" da moderna computação comercial apenas gerenciavam projetos e coordenavam um time muito maior de técnicos. Outro foco que prejudica o entendimento dos fatos é o que se dá ao computador como produto tangível, ainda que seja o software o que permita a essas máquinas serem tão flexíveis em seus usos e aplicações. É através das interfaces de software que se dá a maior parte das interações com essas máquinas.

Antes do emprego de máquinas como o computador, as mulheres já atuavam na Computação, na função de "computadoras", fazendo cálculos balísticos "à mão". Nos Estados Unidos elas trabalhavam no ENIAC (sigla de Electronic Numerical Integrator and Computer), e eram chamadas de ENIAC girls. No Reino Unido, o mesmo modelo de trabalho era utilizado, em Bletchley Park no projeto Colossus com o computador Mark I. Esse trabalho era comumente considerado de menor importância, algo próximo do chão de fábrica, e gerenciado por engenheiros homens (LIGHT, 1999; ENSMERGER, 2010).

A própria gênese das palavras hardware e software tem estreita ligação com os valores e significados atribuídos à atividade naquele período. Segundo Ensmenger, "hard" não coincidentemente designava os trabalhos de engenharia relacionados ao projeto físico dos componentes (trabalho reservado aos homens), e "soft" eram trabalhos secundários envolvendo a programação dessas máquinas e, portanto, relegado às mulheres.

Segundo Paul Edwards:

\begin{abstract}
"Hard" e "soft" são palavras excepcionalmente ricas que cobrem uma variedade de campos conceituais abrangentes. "Hard", de acordo com o dicionário, inclui entre seus cinquenta e quatro significados os de não suave; difícil; laborioso; que requer esforço, energia e persistência; ruim; duro ou severo, não amigável; severamente realista, desapaixonado. "Soft" pode ser definido como não duro, facilmente penetrável; suave e agradável ao toque; prazeiroso; gentil, receptivo, compassivo; responsável ou empático ao sentimento alheio; sentimental; não forte, delicado (o exemplo dado é "Ele era delicado demais para os Fuzileiros Navais"); fácil; submisso. Hard e soft também possuem óbvias conotações sexuais. (In: LERMAN et al, 2003. p. 180) ${ }^{37}$.
\end{abstract}

36 Sigla de Chief Executive Officer, cargo no topo da hierarquia empresarial. Em português, corresponde ao cargo de Diretor Executivo.

37 Tradução livre do original: "'Hard' and 'soft' are exceptionally rich words that covera variety of overlapping conceptual fields. 'Hard,' according to the dictionary, includes among its fifty-four uses the meaning not soft; difficult; troublesome; requiring effort, energy, and persistence; bad; harsh or severe, unfriendly; sternly realistic, dispassionate. 'Soft' may be glossed as not hard, easily penetrated; smooth and agreeable to touch; pleasant; gentle, warm-hearted, compassionate; 
Esta clara divisão sexual do trabalho ajuda a entender como e porque, com a crescente importância do papel do software na informática a partir dos anos 1960, consolidada nos anos 1980 com a computação pessoal, o trabalho de programação foi sendo pouco a pouco masculinizado, levando inclusive a crenças populares equivocadas de que as mulheres não teriam interesse ou mesmo seriam portadoras de uma falta de habilidade inata própria de seu sexo para esse tipo de atividade (LIGHT, 1999).

Nesse contexto da Segunda Guerra Mundial houve uma grande mudança no papel das mulheres e de suas atividades laborais. Chamadas a trabalhos anteriormente atribuídos a homens, também nas engenharias isso ocorre. Jennifer Light (1999), em um artigo que trata especificamente do papel delas nessa área, destaca a multitude de propagandas e campanhas do período, convocando as mulheres ao trabalho de pesquisa. No entanto, a maior presença de mulheres nessas áreas de modo algum representa uma maior equidade nas relações trabalhistas e de pesquisa de homens e mulheres, nem na distribuição e relevância das atividades desempenhadas por cada um deles.

Dessas primeiras programadoras esperava-se que adaptassem planos balísticos já conhecidos e largamente utilizados à linguagem de máquina, cálculo que antes era feito manualmente por mulheres como elas a serviço de engenheiros homens. Conhecidas como "operadoras" ou "codificadoras", ao contrário do que seu espaço na história pode levar a supôr, seu trabalho demandava grandes conhecimentos em matemática e lógica. Ainda que houvesse uma bem definida divisão nominal entre os trabalhos "hard" e "soft", o trabalho dessas mulheres exigia, além de conhecimentos avançados em cálculo, muita familiaridade com os componentes eletrônicos da máquina, que era operada diretamente em baixo nível. Assim, o trabalho daquelas operadoras era duplamente complexo, mas seu legado na história foi subestimado.

A existência dessa mão de obra bastante especializada de mulheres se deve, segundo Margaret Rossiter (in: LIGHT, 1999), ao crescimento da demanda por pesquisadores, à falta de homens - que naquele momento histórico específico pegavam em armas -, ao baixo orçamento destinado a pesquisa e à grande disponibilidade de mulheres com curso superior nos Estados Unidos. Como meras operadoras técnicas, essas mulheres não detinham sua parte nos créditos de pesquisas que ajudaram a desenvolver nem tinham participação nas associações que os pesquisadores para quem trabalhavam eram afiliados. Isso acontecia não apenas no centro de pesquisa do ENIAC e do Colussus, mas também em outras áreas de pesquisa científica em que a presença das mulheres cresceu neste período. Mas essa invisibilização das assistentes e o reconhecimento de sua participação apenas como categoria subalterna não era pontual nem própria deste período específico (SCHIEBINGER, 2001): era, de fato, uma tradição herdada de tempos anteriores, que remonta ao processo de estabelecimento da universidade como o legítimo centro difusor e gerador do conhecimento. Assim, essas mulheres não tinham seu trabalho na produção científica reconhecido e, portanto, não tinham melhores

responsive or sympathetic to the feelings of others; sentimental; not strong, delicate (the example given in 'He was too soft for the Marines'); easy; submissive. Hard and soft also have obvious sexual connotations." 
oportunidades de trabalho nem chances de crescer profissionalmente. Essas "auxiliares de laboratório" existiam oficialmente apenas em vagas citações em que não apareciam de modo nominal, mas como parte de um coletivo amorfo de pesquisadoras anônimas, sempre infantilizadas sob a alcunha plural de "garotas" (girls) (LIGHT, 1999; ENSMENGER, 2010).

Após o fim da guerra e com a volta dos homens dos campos de batalha, o próprio emprego dessas mulheres na Computação mudou radicalmente. Segundo Light (1999, p. 479), "uma avalanche de materiais incitava as mulheres a abandonar o trabalho". Logo, as mulheres foram sendo substituídas por homens em suas funções de operadoras, computadoras e criptógrafas, e seus esforços nessas áreas foram cada vez mais sendo direcionados ao ensino e à educação. A partir de meados dos anos 60 houve uma mudança de importância do papel do software na informática e a consequente reconfiguração da atividade de programação de um trabalho considerado essencialmente feminino para um trabalho masculino.

Com o advento de linguagens de programação de alto nível e capazes de funcionar em mais de uma máquina, e o desenvolvimento dos compiladores nos anos 1960, e o advento da computação pessoal nos anos 1970 e 1980, os programas de computador tornaram-se produtos. O período em que a atividade passou a representar lucros substanciais coincidiu com a exclusão das mulheres da profissão, e também com a elevação dessa categoria profissional a um status social mais elevado (ERSMENGER, 2010). Percebe-se então que, à medida que uma área do conhecimento se profissionaliza, se institucionaliza, e adquire status, a atuação das mulheres nessa área, anteriormente admitida e necessária, se reduz e se concentra em áreas menos valorizadas social e economicamente (CARVALHO, CASCAES \& SPANGER, 2009).

Algumas mulheres, no entanto, jamais abandonaram a atividade e até mesmo tiveram algum destaque, ainda que não da mesma forma que seus colegas do sexo masculino. É o caso de nomes como Betty Snyder (uma das seis ENIAC Girls originais) e Grace Hopper (que participou da criação do primeiro compilador, para a linguagem de programação $C O B O L$ ), esta última tendo ganho altas condecorações do exército americano em função de sua atuação (ERSMENGER, 2010).

\section{Resultados}

As entrevistas realizadas revelaram um grande número de ideias comuns a todas as mulheres entrevistadas, muito mais que diferenças. Essas mulheres são bem articuladas, e não hesitaram em relatar suas experiências. Apesar do registro em vídeo, elas se mostraram dispostas a contar suas histórias e se fazerem ouvidas num ambiente onde são minoria, e onde se percebem como exceções.

O primeiro contato com a Computação das mulheres entrevistadas geralmente se deu por pessoas próximas que Ihes sugeriram trabalhar na área devido à sua desenvoltura nas disciplinas escolares das Ciencias Exatas, ou por um contato breve e estimulante em cursos ou feiras de profissões promovidas por instituições de ensino superior, em conjunto com uma curiosidade própria de pesquisar sobre a atividade. Em alguns casos, essa influência veio do conjuge, namorado ou namorada, ou ainda de professores que fizeram a sugestão. Mas nem sempre essas mulheres tiveram uma história de vida de envolvimento ou afinidade pelas 
Exatas e pelo cálculo. Ainda assim, elas decidiram arriscar na profissão, mesmo não tendo nenhuma identificação ou predisposição prévia com áreas afins à Computação. Não obstante terem essa desenvoltura, elas também relatam possuir outros interesses e outras habilidades em áreas diversas, e por vezes contam que tiveram sérias dúvidas na escolha da profissão. Fatores tais como remuneração média, estabilidade financeira e disponibilidade de vagas no mercado de trabalho também pesaram em sua decisão.

Mesmo que algumas delas não tenham sofrido ou presenciado situaç,ões de discriminação, ou que não reconheçam a presença dessa discriminação nas variadas situaç̧ões que descreveram vivenciar, elas se sabem como parte de um grupo diferente, tratado de forma diferente, sobre o qual se colocam expectativas diferentes, ainda que não vejam isso como uma coisa necessariamente ruim. Além disso, elas têm plena noção de que existe socialização diversa para homens e mulheres, e que essa socialização vem desde os primeiros anos de vida. Ainda que essa socialização não seja recebida e adotada por igual por homens e mulheres, ela é vista como padronizadora de comportamentos para cada um dos sexos. Mesmo assim, há sinais em suas falas de que para certas atividades e habilidades específicas, elas acreditam existir uma predisposição inata, mas não necessariamente ligada ao dimorfismo sexual da espécie humana.

As entrevistadas relatam sentir muita falta da presença de mulheres, de se ver e de se reconhecer entre os colegas. Por mais que encontrem formas de ignorar a pressão, o peso dos estereótipos e as piadas decorrentes deles, elas sentem que faltam mulheres, pessoas com vivencias e experiencias parecidas com as delas nos ambientes profissional e acadêmico. As piadas existem, ainda que - segundo elas - não necessariamente com intenção de ofender, mas sem dúvida incomodam. Elas então acabam por criar estratégias para ignorá-las ou, pelo menos, não serem pessoalmente afetadas pelos chistes e brincadeiras dos homens. Uma das entrevistadas comenta que "é assim mesmo" e que a área "é uma conversa entre homens". Quando relatando casos em que houveram chistes, todas as mulheres narraram experiencias parecidas: em um primeiro momento há um incômodo - que varia em intensidade conforme a entrevistada, mas que existe -, seguido do que algumas delas chamam de "blindagem". Essa "blindagem" surge, aparentemente, de uma percepção de que elas estão em menor número e, portanto, em um ambiente onde não podem contar com o apoio de outras pessoas que tenham experiencias e vivencias parecidas com as delas. Em algumas entrevistas, as participantes relataram que, com o tempo, a frequencia destas piadas começou a arrefecer, seja pela convivencia dos colegas homens com as colegas mulheres e a progressiva descontrução dos mitos - "com o andar ali da carruagem, vendo que tava todo mundo ali no mesmo barco e que a gente conseguia fazer tudo da mesma forma que eles, isso foi meio que deixado de lado" - , seja pela prova de valor por parte delas de forma mais incisiva. As mulheres, então, precisam provar seu valor e acabam desenvolvendo uma convivencia mais pacífica com os homens, que progressivamente se solidifica com o tempo. Entretanto, a cada novo ambiente, novo emprego, nova turma de colegas universitários, esse processo precisa ser repetido.

Ainda sobre piadas, algo percebido tanto por mulheres do grupo discente quanto do grupo docente é a presença maçica de chistes de caráter homofóbico. Entretanto, o alvo desses 
chistes em sua maioria não são as mulheres homossexuais - que os homens costumam fetichizar -, mas os homens, independente de orientação sexual. Até mesmo aqueles homens que apresentam comportamento homossexual aparecem como emissores de piadas deste tipo; "muitos dos meninos [...] não são héteros, eles não se assumem porque tem essa pressão social do ser macho, do fazer curso de homem". Entretanto, duas das entrevistadas relataram que sentem desconforto pela forma como suas orientaç̃es sexuais por vezes são abordadas pelos homens. Segundo uma delas, alguns colegas "ficam com umas brincadeirinhas, com umas coisas que eu acho bem desnecessárias", e a outra afirmou não participar mais de eventos sociais com colegas de curso: "Cervejada, eu não vou mais. Eu beijava minha namorada lá e os caras queriam se meter no meio, batendo palma. É ridículo!"

As entrevistadas notam uma preocupação crescente por parte das grandes empresas em incluir mulheres, oferecer oportunidades e flexibilizar horários para que possam conciliar seu trabalho com suas necessidades pessoais, principalmente em relação à particularidades específicas das mulheres - como a gestação, a maternidade e o cuidado com a prole. Porém, com exceção de uma delas, do grupo das discentes, nenhuma questionou essa conciliação dos papéis de mãe e profissional, ou levou em consideração em suas falas uma divisão mais igualitária de tarefas entre homens e mulheres dentro do núcleo familiar, apesar de sempre se falar em uma flexibilização das condições de trabalho por parte dos empregadores. As mulheres continuam, mesmo quando buscam igualdade, tomando para si responsabilidades que deveriam ser divididas entre os cônjuges ou outros membros da família. A entrevistada questionadora destaca que uma mulher pode até sair do papel atribuído a ela, mas não muito.

Uma opinião geral das entrevistadas sobre o porquê de a área da computação ter perdido o apelo que tinha nas décadas passadas (1980 e 1990) de "profissão do futuro" é a reputação apontada por algumas como injusta e falsa - de ser um curso dificil. Para atrair mais pessoas para a computação, é geral a opinião entre elas de que precisa-se criar mais ações de incentivo já no Ensino Médio, de modo a desmitificar a aura de dificuldade e mostrar que todos são capazes de aprender. Além disso, o desinteresse geral, tanto das mulheres quando dos homens, segundo elas, parte também da forma como as disciplinas de Exatas são lecionadas no período escolar. Uma entrevistada do grupo das docentes declara: "tem muita gente que não quer fazer coisas de Exatas porque tiveram péssimos professores de Matemática".

A mesma entrevistada por muitas vezes ao longo da entrevista comparou disciplinas das Exatas com outras áreas para justificar que a atribuição do caráter "dificil" da computação é injusta: "Eu nunca vi, por exemplo, o curso como dificil. [...] eu acho que Medicina é dificil, porque vocen obrigatoriamente trata de vidas". Mais adiante, ela afirma: "voce quer coisa mais complicada que regras gramaticais da lingua portuguesa? [...] Fatos da História são complicados, porque sempre tem, né, várias visões, vários viéses".

Com relação ao incentivo entre as mulheres especificamente, nota-se a falta de exemplos, role models. Quando perguntadas sobre que exemplos elas citariam em que as mulheres pudessem se inspirar, citam-se sempre as mulheres que fizeram parte da história da computação há bastante tempo e que têm fama consolidada, como Grace Hopper e Ada Lovelace. Citam-se também os chamados "exemplos de corredor": são em geral professoras ou 
colegas de trabalho próximas, por quem nutrem admiração em razão de seu trabalho no ensino e na atuação profissional na área propriamente dita. É interessante notar que estes exemplos não fizeram fama e, em geral, não têm apelo entre as mulheres por conta de quanto dinheiro conseguiram através de seus feitos - como é o caso de exemplos populares como Bill Gates, Mark Zuckerberg ou Steve Jobs -, e sim por causa de suas façanhas intelectuais.

Algumas entrevistadas lamentam também a falta de destaque que seus exemplos e modelos ganham mesmo quando são citadas, e também a forma como perdem o crédito por suas proezas. Falando sobre Ada Lovelace - a quem se atribui a criação do primeiro programa de computador no século XIX, feito para a máquina analítica de Charles Babbage (FRANCIS; FUENGI, 2003) -, uma das entrevistadas declara: "É clássico, e ninguém fala sobre. Não existe. Cadêa moça? Não existe! Por quê, né?"

Com relação ao ambiente universitário, quase não há relatos de comportamento sexista por parte dos professores; apenas um dos depoimentos, do grupo das docentes, conta de uma situação classificada pela entrevistada como pontual e própria daquele indivíduo que foi seu professor nos tempos de estudante. Porém, algumas das mulheres dizem que já ouviram falar de casos nos quais um atrito do tipo aconteceu, tanto nos cursos de computação quanto em outros cursos da área de Exatas, mas nunca que elas próprias tenham presenciado ou vivido.

Todavia, as hostilidades por parte dos colegas de turma são bastante frequentes no âmbito acadêmico, segundo tais narrativas. Em geral, essa hostilidade se dá em forma de deboche. Termo comum presente na maioria das entrevistas é "piada" e suas variantes, principalmente no diminutivo. O teor dessas piadas, conforme relato da primeira entrevista são machistas e sempre no sentido de questionar a presença das mulheres naquele ambiente e no curso superior: "olha só quantos homens têm aqui, isso não é coisa de mulher. Vocês não se enxergam?". No mesmo relato, outra piada relatada, desta vez questionando a legitimidade da escolha do curso de graduação: "vocês vieram aqui caçar marido [...] porque, olha só, tem quatro [mulheres] pra escolher entre trinta e seis [homens]".

Há dois fatores nos depoimentos coletados que podem indicar a presença de uma possível divisão sexual do trabalho dentro da computação. O primeiro deles é a tendencia dos homens de superestimar suas próprias capacidades, ainda que a experiencia não confirme isso (vide BANYARD, 2010). Uma entrevistada relata que se sente incomodada quando algum colega homem se vê como "o rei da computação". O segundo é uma consequência do primeiro: o fato de os homens justificarem suas dificuldades em algumas áreas - geralmente as que fazem parte de disciplinas que envolvem expressão verbal e escrita, onde geralmente têm mais dificuldade (vide FINE, 2005; SINCLAIR, 2006) - dizendo que não têm interesse nelas porque são "fáceis".

Ainda que estes depoimentos não sirvam para provar a existencia de uma tendencia observável, estes exemplos ad hoc podem dar pistas sobre porque tantas mulheres se concentram em áreas espećíficas da Computação, como por exemplo o ensino; "a docência tradicionalmente é uma área das mulheres", afirma uma das entrevistadas do grupo das docentes. Essa imagem frequente da mulher docente pode influenciar as escolhas futuras das 
alunas, uma vez que é nas professoras que as estudantes enxergam suas semelhantes atuando na computação.

Uma docente afirma: "A impressão que eu tenho é que os alunos se sentem mais à vontade com uma professora mulher. [...] quando eles veem uma professorinha chegando bonitinha na sala de aula, parece que eles respiram mais tranquilos". Em outra entrevista, uma docente ressalta que é às professoras mulheres que os alunos e alunas preferem recorrer quando precisam de conselhos ou ajuda, pois enxergam as professoras como mais dotadas de empatia e compreensão. Aqui existem pistas de outra influencia que a imagem da mulher docente pode exercer sobre os alunos e alunas, e também no próprio comportamento das professoras: a percepção de que os estereótipos historicamente associados às mulheres, e mais especificamente às mulheres na docencia - nutridora/cuidadora, compreensiva, maternal etc - ainda se fazem presentes mesmo na graduação. No entanto, esse direcionamento pode ter consequêcias positivas caso essas futuras professoras tenham consciência de seu lugar na profissão e na sociedade e estejam dispostas a mudar esse cenário: existe a possibilidade de que essas mulheres possam formar gerações de profissionais de mente mais aberta em relação às mulheres na tecnociência e na Computação.

Há, nos discursos das mulheres entrevistadas, o reconhecimento unânime de que há menos interesse por parte das mulheres pelas áreas das Exatas e pela Computação em espećífico. Ainda que duas das entrevistadas tenham apontado que habilidades inatas diferentes em homens e mulheres possam influenciar essa escolha, fica evidente nos discursos delas que ainda mais importante que isso é a socialização, pois elas mesmas admitem que o interesse das mulheres pela área pode ser despertado com o estímulo apropriado.

Com relação ao peso da socialização na influencia dos interesses e inclinações intelectuais de ambos os sexos, os exemplos apresentados nos discursos para demonstrar isso são muito semelhantes nos relatos: aparece sempre a figura do menino que, desde pequeno, é incentivado a arriscar-se e aventurar-se nas brincadeiras, e que não recebe reprimendas quando desmonta o brinquedo por curiosidade a respeito de seu funcionamento; e a da menina que, igualmente desde pequena, tem suas atividades, brincadeiras e jogos com um leque muito mais restrito e limitado, com foco no cuidado com os outros e no cultivo da aparencia, e que, por causa disso, demonstra muito mais hesitação no momento de arriscar do que o menino. É muito recorrente nos discursos dessas mulheres frases com construções semelhantes a "desde pequena/pequeno a/o menina/menino é incentivada/incentivado a...".

Considerando a natureza das brincadeiras a que as meninas são incentivadas, as entrevistadas notam que, mesmo enquanto crianças, delas já se exigem responsabilidades de adulto, voltadas ao cuidado com o outro. Em pelo menos uma das entrevistas a participante nota que a questão da socialização exige responsabilidades e posturas diferentes de homens e mulheres. Segundo uma discente, das mulheres desde muito cedo é exigido um amadurecimento mais rápido e um abandono mais precoce da infância, enquanto que homens são educados a desfrutarem por mais tempo de brincadeiras e jogos. A entrevistada diz que "a menina desenvolve mais rápido. Pelo menos quando é criança, a menina de doze anos é melhor que um menino de doze anos". Ela aponta isso como uma das causas do afastamento 
entre as esferas de convivio masculinas e femininas, e a consequente divergencia nos interesses dos dois grupos. Essa percepção das entrevistadas pode ser um indício de uma mentalidade antiga a respeito da infância que ainda sobrevive ${ }^{38}$. Uma entrevistada comentou brevemente a respeito da diferença de maturidade percebida entre os sexos quando fala a respeito dos gracejos que espera encontrar no mercado de trabalho: "É de se esperar que os caras fossem mais maduros, né?". Mais adiante a mesma entrevistada afirma: "as brincadeiras que tinha era vestir a Barbie, maquiar a Barbie, se resumia a isso, entendeu? [...] da menina é pra ser mais 'ah, vamos cuidar, vamos brincar de boneca', esse tipo de coisa. E isso é totalmente aberto, totalmente explícito, é só você parar ali numa vitrine de shopping".

Esse tipo de socialização estaria, segundo observado nas falas das entrevistadas, diretamente na raiz dos modos de trabalho diversos que homens e mulheres utilizam quando atuando na Computação. Também é unaninime a semelhança entre o padrão de trabalho de homens e mulheres observado por cada uma delas: mulheres teriam uma visão mais abrangente no momento de abordar um problema e buscariam evitar cometer erros logo de início nos projetos, enquanto que os homens teriam mais dificuldade em enxergar o todo, concentrando-se em atividades espećificas, uma por vez. Homens, segundo as entrevistadas, tomam os termos "rapidez" e "eficiencia" por sinônimos e, portanto, teriam mais coragem de arriscar mais e menos medo de cometer erros. Em compensação, elas são mais cuidadosas e menos afeitas a se utilizarem de "soluções alternativas", mais sujeitas a erros, que os homens, e dedicam mais tempo do desenvolvimento de um projeto no seu planejamento.

Apesar de acreditarem no poder da socialização como direcionadora dos interesses e dos métodos de trabalho de homens e mulheres, as entrevistadas também acreditam que as experiencias individuais - a quebra de estereótipos em nível pessoal - podem criar perfis diferentes de trabalho independentes do sexo. A socialização, para elas, não seria inescapável, apesar de ter papel crucial. Isso fica evidente em frases como "já é mais da formação da pessoa" e "no geral as pessoas usam métodos ou estilos de trabalho diferentes, independe do gênero". As entrevistas mostram que as mulheres não acreditam que esta diferença de vivencias e modos de atuação sejam necessariamente ruins. Elas percebem o caráter de construto social da tecnologia, e as forças sociais que levam projetos a tomarem certos rumos. Algumas vezes o "ponto de vista" e a vivencia diversa das mulheres são ressaltados como qualidades que têm sido buscadas na área da Computação, pelo menos nas grandes multinacionais.

\section{Conclusão}

Existem muitos indivíduos envolvidos na busca por determinar até onde vão as capacidades e realizações intelectuais das mulheres ou retratar seus feitos, seja fazendo pesquisas ou tecendo conjecturas. Raramente, no entanto, são elas próprias quem protagonizam esta busca. Quando se trata de mulheres na tecnociência, é abundante o número de relatos, pesquisas,

38 Em uma pequena história dessa fase da vida escrita por Shulamith Firestone, a autora diz que, quando as crianças passaram a ser tratadas de forma bastante diferenciada por volta século XVII - com códigos de conduta e de vestimenta próprios -, "o conceito de infância não se aplicava às mulheres", pois "[a]s meninas não tinham razão para passar por mudanças de trajes, quando não havia nada em direção a que elas crescerem" (FIRESTONE, 1976. p. 96-97). 
estatísticas, narrativas históricas - enfim, fatos - que mostram que mulheres foram colocadas em uma situação de subordinação tão tóxica e dificil de se livrar que muitas delas podem até mesmo acabar reproduzindo discursos e práticas criados para mantế-las em tal situação. Mesmo assim, o tempo todo surgem pesquisas que corroboram a ideia patriarcal de que características estereotipicamente associadas às mulheres são naturais e inatas, e se localizam em algum recanto cerebral escondido, e têm seus resultados reproduzidos exaustivamente na mídia, mesmo que sejam altamente questionáveis. O principal resultado prático dessas pesquisas - em geral, conduzidas por homens dentro de campos de estudo tradicionalmente masculinos, realizadas em institutos comandados por homens, e que apenas recentemente receberam críticas com viés feminista - é a manutenção de um sistema de opressão baseado no sexo de nascimento, em que uma casta é subordinada à outra.

Ainda que as mulheres não se conformem ou não se contentem, e busquem expandir os horizontes da forma social em que as querem encaixar, tais restrições exercem um papel fundamental na manutenção das desigualdades entre os sexos, uma vez que seu domínio não é apenas sócio-politico, mas também simbólico. Tal domínio tem por efeito a criação da passividade que é apontada como inata e causa primeira das limitações das mulheres nos empreendimentos intelectuais. Nesta passividade artificialmente criada, a mulher "se torna símbolo disso, símbolo daquilo: mãe da terra, puta do universo; mas ela nunca se torna ela mesma porque é proibido a ela fazer tal coisa" (DWORKIN, 1989. p. 128) ${ }^{39}$.

É visivel que a tecnociencia - mediada socialmente e guiada nas direç̃oses em que apontam aqueles que detém o poder - e a tecnologia computacional têm sido apropriadas e vêm servindo aos propósitos das mulheres, a despeito das forças que as queiram manter alienadas e afastadas dessas atividades. Mesmo que os valores sutilmente veiculados na Computação ainda sejam majoritariamente atrelados aos homens, a despeito disso elas vêm abrindo caminhos e rompendo fronteiras; o caminho trilhado pelas mulheres que futuramente queiram se aventurar na área pode ser bem mais fácil.

Por mais que as vontades individuais exerçam uma força poderosa na vida dessas mulheres no que diz respeito à quebra de barreiras e busca de oportunidades na vida em geral e na tecnociencia em particular, essas mudanças dificilmente ocorrerão caso não aconteçam mudanças estruturais nas relaç̃oes de trabalho, sociais, e também dentro do núcleo familiar, em uma sociedade que se alicerça sobre uma divisão hierárquica de sexos e dos saberes. Essa necessidade mostrou-se patente na fala das docentes entrevistadas, ao evidenciarem a importancia de o trabalho ser conciliável com o cuidado com a família. Ainda que algumas funções no núcleo familiar sejam por vezes indissociáveis das mulheres - gestação, amamentação -, as demais tarefas do lar precisam ser repensadas e redistribuídas, e não simplesmente acrescentadas à lista de afazeres da profissional mulher na computação. "Para trazer as mulheres para a ciência, precisamos reestruturar os mundos profissional e doméstico" (SCHIEBINGER, 2001. p. 196).

39 Tradução livre do original: "[She] becomes symbol of this, symbol of that: mother of the earth, slut of the universe; but she never becomes herself because it is forbidden for her to do so." 
Para a emancipação completa das mulheres - luta iniciada de maneira sistemática, organizada e com força política notável no Brasil já no século XIX com os movimentos em busca do sufrágio universal (TELES, 1999) - , é necessária uma completa reestruturação da sociedade. Por mais que a luta e o movimento de libertação das mulheres como se conhece hoje tenha ainda relativamente pouco tempo de vida, é possível notar ao longo da história focos de resistência individual e coletiva, e uma incrível capacidade das mulheres para agir nas brechas e fazer impor sua vontade, mesmo com restrições, e mesmo com tantas responsabilidades e obrigaç̃ões - importantes mas subvalorizadas - delegadas a elas. Entretanto, ainda que essa força motriz individual seja poderosa e mostre a capacidade das mulheres em realizar grandes feitos, ela é por si só insuficiente e ineficiente no sentido de tornar essa libertação acessível a todas. Junte-se a isso o fato de que as várias caracteríisticas dos vários agrupamentos de mulheres - negras, lésbicas, pobres - levam a vários graus diferentes de necessidades e poder de agencia em contextos espećificos, é evidente que é preciso uma ação conjunta, coletiva, para que a libertação das mulheres seja efetiva.

O antigo slogan do movimento feminista, "o pessoal é político", indica como essa mudança pode continuar e, talvez, o lugar onde ela tem se mostrado ainda mais necessária: no núcleo familiar, nas relações sociais mais próximas, mais afetivas e mais afetadas pelas grandes responsabilidades e, também, pelas grandes culpas. Popularizado com o artigo de Carol Hanisch, publicado na antologia "Notes from de Second Year: Women's Liberation" em 1970, buscando apontar que boa parte dos problemas ditos pessoais da mulheres tinham causas muito maiores, exteriores e independentes de suas vontades (HANISCH, 2006), esta frase aponta para de que forma essa mudança pode acontecer: na busca por uma sociedade que se estruture de modo a enxergar mulheres como seres humanos completos; na preocupação por uma distribuição mais igualitária das tarefas domésticas e do cuidado com a prole assumidas pelos vários membros de uma família; na tomada, por parte dos homens, da responsabilidade que lhes cabe enquanto classe - mesmo que individualmente pensem não contribuir de forma ativa para a manutenção das disparidades, têm sim um papel fundamental, ainda que inconsciente, nessa desigualdade (SCHOLZ, 1996) - , e precisam tomar posição e decidir agir em favor das mulheres sem buscar o protagonismo de uma luta que é delas, e somente delas.

\section{Referências}

BANYARD, Kat. The Equality Illusion: The Truth about Women and Men Today. Londres: Faber and Faber, 2010.

BIJKER, Wiebe E.; PINCH, Trevor. "The Social Construction of Facts and Artifacts: Or How The Sociology of Science and the Sociology of Technology Might Benefit Each Other". In: BIJKER, Wiebe E.; HUGHES, Thomas P.; PINCH, Trevor; DOUGLAS, Deborah G. The Social Construction of Technological Systems. Cambridge: MIT Press, 1987.

CALEFFE, Luiz Gonzaga; MOREIRA, Herivelto. Metodologia da Pesquisa para o Professor Pesquisador. Segunda edição. Rio de Janeiro: Lamparina, 2008. 
CARVALHO, Marilia Gomes; CASCAES, Tânia Rosa F.; SPANGER, Maria Aparecida Fleury Costa. "Ciência e Tecnologia sob a Ótica de Gênero". In: CARVALHO, Marília Gomes de; CASAGRANDE, Lindamir Salete; LUZ, Nanci Stancki da (org). Construindo a Igualdade na Diversidade: gênero e sexualidade na escola. Primeira edição. Curitiba: Editora UTFPR, 2009.

DE DECCA, Edgar Salvadori. O Nascimento das Fábricas. Décima edição. São Paulo: Editora Brasiliense, 1995.

DWORKIN, Andrea. Pornography: Men possessing women. Nova York: Plume, 1989.

EDWARDS, Paul N. "Industrial Gender: Soft/Hard". In: LERMAN, Nina; MOHUN, Arwen; OLDENZIEL, Ruth. Gender and Technology: a reader. Baltimore: The Johns Hopkins University Press, 2003.

ENSMENGER, Nathan. The Computer Boys Take Over: computers, programmers, and the politics of technical expertise. Cambridge: MIT Press, 2010.

FINE, Cordelia. Delusions of Gender: The Real Science Behind Sex Differences. Nova York: Icon Books, 2005.

FIRESTONE, Shulamith. A Dialética do Sexo: um estudo da revolução feminista. Tradução de Vera Regina Rabelo Terra. Coleção de Bolso. Rio de Janeiro, Editorial Labor do Brasil, 1976.

FRANCIS, Jo; FUENGI, John. Lovelace \& Babbage and the Creation of the 1843 'Notes'. IEEE Annals of the History of Computing. IEEE Computer Society. v. 25. n. 4. Outubro de 2003. Disponível em: <http://dl.acm.org/citation.cfm?id=1436041> - Acesso em 3 de junho de 2014.

HALL, Stuart. Representation: Cultural representations and signifying practices. Londres: SAGE Publications, The Open University, 2003.

HANISCH, Carol. The Personal is Political: The Women's Liberation Movement classic with a new explanatory introduction. CarolHanisch.org. 2006. Disponivel em: <http://carolhanisch.org/CHwritings/ PIP.html> - Acesso em 3 de junho de 2014.

JEFFREYS, Sheila. Beauty and Misogyny: harmful cultural practices in the West. Londres, Nova York: Routledge, 2005.

LIGHT, Jennifer S. "When Computers Were Women". In: Technology and Culture. v. 39. n. 3. Maryland: The Johns Hopkins University Press, 1999. Disponível em: <http://labweb.education.wisc.edu/steinkuehler/ elpa940/readings/Light.pdf> - Acesso em 7 de dezembro de 2012.

McGAW, Judith A. "Why Feminine Technology Matter". In: LERMAN, Nina; MOHUN, Arwen; OLDENZIEL, Ruth. Gender and Technology: a reader. Baltimore: The Johns Hopkins University Press, 2003.

SCHIEBINGER, Londa. O Feminismo Mudou a Ciência? Tradução de Raul Fiker. Bauru: EDUSC, 2001.

SCHOLZ, Roswitha. O Valor é o Homem: Teses sobre a socialização pelo valor e a relação entre os sexos. Tradução de José Marcos Macedo. Revista Novos Estudos - CEBRAP. n. 45. Julho de 1996. p. 15-36. Disponivel em: <http://obeco.planetaclix.pt/rst1.htm> - Acesso em 17 de marco de 2014.

SINCLAIR, Stacey; HARDIN, Curtis D. e LOWERY, Brian S. Self-Stereotyping in the Context of Multiple Social Identities. Journal of Personality and Social Psychology. v. 90. n. 4. p.529-542. 2006. Disponível em: <https://psych.princeton.edu/psychology/research/sinclair/pubs/self\%20stereo\%20and\%20multiple \%20identiti es.PDF> - Acesso em 10 de junho de 2013.

TELES, Maria Amélia de Almeida. Breve História do Feminismo no Brasil. Coleção Tudo é História. São Paulo: Editora Brasiliense, 1999.

VIEIRA PINTO, Álvaro. Ciência e Existência: problemas filosóficos da pesquisa científica. Rio de Janeiro: Paz e Terra, 1979.

VIEIRA PINTO, Álvaro. O Conceito de Tecnologia. Volume 1. Rio de Janeiro: Editora Contraponto, 2005. 
WAJCMAN, Judy. El Tecnofeminismo. Tradução de Magalí Martinés Solimán. Primeira Edição. Madri: Ediciones Cátedra, 2006.

WINNER, Langdon. The Whale and the Reactor: a search for limits in an age of high technology. Chicago: University of Chicago Press, 1986. Disponível em: <http://zaphod.indlab.umd.edu/docSeminar/pdfs/ Winner.pdf $>$. Acesso em 5 de dezembro de 2012.

WOLF, Naomi. O Mito da Beleza: Como as imagens de beleza são usadas contra as mulheres. Tradução de Waldéa Barcellos. Rio de Janeiro: Rocco, 1992.

YIN, Robert K. Estudo de Caso: Planejamento e Métodos. Tradução de Ana Thorell. Quarta edição. Porto Alegre: Bookman, 2010.

Submetido para avaliação em 06 de outubro de 2015 Aprovado para publicação em 12 de abril de 2016.

\section{Fabiane Alves de Lima}

Fabiane Alves de Lima - Universidade Tecnológica Federal do Paraná, Curitiba, BR-PR.

E-mail: fabianelim@gmail.com 